\title{
Prevenção do suicídio no Brasil:
} como estamos?

\section{| ${ }^{1}$ Eder Samuel Oliveira Dantas |}

\author{
${ }^{1}$ Hospital Universitário Onofre Lopes, Universidade Federal do Rio Grande do Norte. Natal-RN, Brasil (edersamuel_rn@hotmail.com). \\ ORCID: 0000-0002-6595-6105 \\ Recebido em: 02/06/2019 \\ Aprovado em: 25/07/2019 \\ Revisado em: 30/07/2019 \\ DOI: http://dx.doi.org/10.1590/S0103-73312019290303
}

O suicídio é um fenômeno social bastante complexo e é considerado um grave problema de saúde pública no mundo (WHO, 2014). Muito embora as maiores taxas de ocorrência do suicídio se concentrem em países da Ásia e da Europa, o Brasil possui uma das maiores taxas em números absolutos em todo o mundo. No período de 2011 a 2015, foram registrados 55.649 óbitos por suicídio no Brasil, com uma taxa geral de 5,5/100 mil habitantes, variando de 5,3 em 2011 a 5,7 em 2015, o que dá uma ideia da magnitude da situação que deve ser enfrentada (BRASIL, 2017).

Ainda assim, para além dos números de mortes supramencionados, é importante entender que o comportamento suicida, expresso em ideação e tentativas de suicídio, torna esta problemática ainda mais desafiadora, pois os aspectos que circunscrevem tal comportamento englobam questóes biológicas, ambientais, psicológicas e sociais. Por esta razão, há o impacto nos serviços de saúde, escolas, famílias e comunidades em que os indivíduos estão inseridos, exigindo políticas públicas eficazes para a prevenção do suicídio no país. Estima-se ainda, que a cada suicídio consumado, pelo menos seis pessoas são atingidas negativamente pelo ato fatal (BOTEGA, 2014; MINAYO; MENEGHEL; CAVALCANTE, 2012).

Se pensarmos na extensão territorial brasileira, na diversidade cultural, nos fatores socioeconômicos, nas desigualdades sociais e na distribuição de recursos públicos e de serviços, teremos mais clareza sobre o quanto são necessárias 
estratégias de prevenção do suicídio que englobem esses diferentes aspectos em um país de dimensão continental, e que vive, atualmente, constantes mudanças e incertezas políticas e econômicas, em uma escalada conservadora nos costumes e com caráter armamentista.

É importante lembrar que, ao longo dos anos, algumas estratégias no campo da saúde foram adotadas no Brasil, com o intuito de prevenir o suicídio, especialmente após os anos 2000. Manuais direcionados a profissionais de saúde mental, atenção básica, mídia, educação e conselheiros foram lançados pelo Ministério da Saúde, seguindo inclusive os direcionamentos da Organização Mundial da Saúde (OMS) e da Organização Pan-americana da Saúde (OPAS). Estas produziram documentos importantes que auxiliam os países nas formulaçóes de políticas de prevenção do suicídio. Além disso, todos os Estados integrantes da OMS presentes no Plano de Ação de Saúde Mental 2013-2020 pactuaram uma redução de 10\% nas taxas de suicídio até 2020.

O relatório da OMS intitulado Prevenção do suicídio: um imperativo global incentiva que cada país desenvolva e reforce estratégias de prevençâo de abordagem multissetorial (WHO, 2014). Dessa forma, no primeiro semestre de 2019, foi sancionada a Lei no 13.819/2019, instituindo a Política Nacional de Prevenção da Automutilação e do Suicídio no Brasil (PNPAS). Esta constitui um marco legal para possíveis regulamentaçôes (decretos, portarias) que possam ser implementadas no território nacional, a fim de prevenir o suicídio (BRASIL, 2019).

No entanto, faz-se um contraponto paradoxal: está presente como um dos objetivos da referida lei, no Art. $3^{\circ}$, em seus capítulos IV e V, a adequada abordagem psicossocial às pessoas envolvidas com o comportamento suicida:

[...] garantir o acesso à atençáo psicossocial das pessoas em sofrimento psíquico agudo ou crônico, especialmente daquelas com histórico de ideação suicida, automutilaçóes e tentativa de suicídio; abordar adequadamente os familiares e as pessoas próximas das vítimas de suicídio e garantir-lhes assistência psicossocial; [...]

Todavia, é incongruente o fato de que outras políticas, essenciais para tornar a prevenção do suicídio efetiva - como a Política Nacional sobre Drogas e a Política Nacional de Saúde Mental -, tenham intenção, em suma, de "ultraespecializar" as demandas de saúde mental e de retirar os espaços próprios de ressocialização dos indivíduos com transtornos mentais, a exemplo do seu território, trazendo à cena 
principal dessas políticas, raízes históricas do modelo biomédico e manicomial da psiquiatria (ABRASCO, 2019).

De outro lado, parece ineficaz o fato de a PNPAS, em seu Art. 3ㅇ, Cap. VI, objetivar: "informar e sensibilizar a sociedade sobre a importância e a relevância das lesôes autoprovocadas como problemas de saúde pública passíveis de prevenção”. Sabe-se que uma das formas mais eficazes de se realizar prevenção universal do suicídio é diminuir o acesso da população geral a meios letais de perpetração do ato suicida, como os pesticidas, agrotóxicos e armas de fogo (BOTEGA, 2014).

No entanto, já no primeiro semestre de 2019, por meio do Decreto n o 9.785, de 7 de maio, a posse, o porte e a venda de armas de fogo no Brasil foram liberados em massa, contradizendo os pressupostos da PNPAS. Também em 2019, houve recorde histórico de liberação de comercialização de agrotóxicos, considerados bastante nocivos à saúde humana e um meio de alta letalidade de suicídio, utilizado principalmente em regiōes que têm a agricultura como principal atividade, a exemplo do Sul do país (BERTOLOTE, 2006).

Portanto, partindo-se da premissa de que, para prevenir o suicídio no Brasil ou em qualquer lugar do mundo, se faz necessária articulação intersetorial, alinhando políticas públicas de áreas prioritárias, como a saúde, educação e assistência social, entende-se que há urgência de mudanças estruturais no país para além da instituição da Política Nacional de Prevenção da Automutilação e Suicídio, que devem partir, especialmente, da valorização da vida humana em sua totalidade, que possam tornar o Brasil um local mais igualitário e em condições habitáveis para toda sua população.

\section{Referências}

ASSOCIAÇÃO BRASILEIRA DE SAÚDE COLETIVA. Sobre as mudanças na Politica Nacional de Saúde Mental e nas Diretrizes da Politica Nacional sobre Drogas. Rio de Janeiro: Abrasco, 2019. Disponível em: <https://www.abrasco.org.br/site/outras-noticias/saude-dapopulacao/sobre-as-mudancas-na-politica-nacional-de-saude-mental-e-nas-diretrizes-dapolitica-nacional-sobre-drogas/39619/> Acesso em: 30 maio 2019.

BERTOLOTE, J. F. et al. Suicide, suicide attempts and pesticides: a major hidden public health problem. Bulletin of the World Health Organization, v.84, n. 4, p. 260-261, 2006.

BOTEGA, N. J. Comportamento suicida: epidemiologia. Psicologia USP, v.25, n. 3, p. 231-36. 2014. 
BRASIL. Lei no 13.819, de 26 de abril de 2019. Institui a Política Nacional de Prevenção da Automutilação e do Suicídio, a ser implementada pela União, em cooperação com os Estados, o Distrito Federal e os Municípios; e altera a Lei no 9.656, de 3 de junho de 1998.Vigência. Brasília, DF: Diário Oficial da União, 26 abr. 2019. Seção 1, p. 1.

Ministério da Saúde, Secretaria de Vigilância em Saúde. Boletim Epidemiológico: Suicidio. Saber, agir e prevenir, v.40, n. 38, 2017.

MiNAYO, M. C. S.; MENEGHEL, S. N; CAVALCANTE, F. G. Suicídio de homens idosos no Brasil. Ciênc. saúde coletiva. Rio de Janeiro, v. 17, n. 10, p. 2665-2674, 2012.

WORLD HEALTH ORGANIZATION. Preventing suicide: a global imperative. Geneva: WHO, 2014. 